\title{
EFEKTIVITAS INTERVENSI BRISK WALKING: LITERATURE REVIEW
}

1| Dwi Esti Handayani, 2| Kadek Ayu Erika, 3| Andi Masyitha Irwan

Email : kadek20 uh@yahoo.com

\begin{abstract}
Introduction: Physical inactivity and sedentary behavior contribute greatly to an increase in the burden of non-communicable diseases. One of the recommended exercises for increasing physical activity is brisk walking. This exercise is more accessible and acceptable than other forms of physical activity training. Methods: Literature search was conducted on 4 database; PubMed, Scopus, ScienceDirect and ProQuest. Articles reported in English for the last 5 years, brisk walking related to various health problems in patients and article published in randomized control trial. Results: A total of 729 articles were supported from four database searches and only 9 articles met the inclusion criteria. Some of the benefits that have proven to be effective evidence-based are to reduce fatigue levels especially in patients with breast cancer undergoing chemotherapy and high-level industrial workers. Effectively controlling blood pressure and reducing other cardiovascular risks. Other effectiveness such as prevention of postural disorders and reducing the risk of falling, increasing the ability and endurance to walk (exercise tolerance) by up to 45\%. The effects of using brisk walking has it has to 2 months to 6 months after exercise. Conclusion The benefits of this exercise are primarily in reducing cardiovascular risk (including hypertension and blood sugar levels). This exercise is also recommended for anyone and is not required to be performed at home.
\end{abstract}

ARTICLE INFO

Keywords:

Brisk walking; Intervention; cardiovascular risk; Fatigue; Balance

DOI:

$\underline{10.24252 / \text { kesehatan.v13i2. } 16311}$

\section{Pendahuluan}

Penyakit Tidak Menular (PTM) atau dikenal dengan Non Communicable Disease (NCD) semakin menjadi beban kesehatan, pembangunan ekonomi dan kesejahteraan sebagian besar populasi masyarakat saat ini (WHO, 2017). NCD merupakan penyebab utama kematian di tingkat global (2). Hal ini menyebabkan NCD menjadi salah satu tantangan utama Sustainable Development Goals (SDGs) dengan mengurangi kematian dini akibat NCD (3). Beberapa penyakit yang umum pada NCD adalah penyakit kardiovaskuler, diabetes mellitus, kanker dan penyakit pernapasan kronik (4).

NCD akan semakin meningkat pada orang yang merokok, menggunakan alkohol, diet yang tidak sehat, obesitas, tekanan darah tinggi hingga ketidakaktifan fisik (WHO, 2017). Ketidakaktifan fisik (Physical Inactivity) diidentifikasi sebagai salah satu faktor risiko untuk kematian global. Ketidakaktifan fisik meningkat di banyak negara dengan implikasi besar terhadap prevalensi penyakit tidak menular (NCD) dan kesehatan umum populasi di seluruh dunia (5). Tren saat ini dalam studi aktivitas fisik dan ketidakaktifan fisik menjadi pusat perhatian. Ketidakaktifan fisik dan perilaku menetap (Sedentary Behavior) berkontribusi besar pada peningkatan beban penyakit NCD (6).

Hidup dengan gaya hidup yang menetap merupakan faktor risiko independen untuk beragam penyakit. Oleh karena itu, sangat penting untuk melakukan aktivitas fisik, bahkan dengan sedikit aktivitas fisik akan memiliki dampak positif pada kesehatan (7). Beberapa jenis latihan yang dapat meningkatkan aktivitas fisik seperti, aerobik, anaerobic, penguatan otot, penguatan tulang dan keseimbangan (8). Salah satu latihan yang direkomendasikan dari latihan aerobic adalah brisk walking (jalan cepat). Latihan ini tidak memiliki keterampilan, fasilitas atau persyaratan peralatan dan lebih mudah diakses dan diterima dibandingkan bentuk latihan aktivitas fisik lainnya (9).

Brisk walking merupakan latihan jalan cepat setidaknya $3 \mathrm{mph}(4.83 \mathrm{~km} / \mathrm{jam})$ dan digolongkan dalam aktivitas fisik intensitas sedang (moderate intensity). Brisk walking terbukti secara ilmiah efektivitasnya dan dapat menjadi intervensi yang dapat mempromosikan aktivitas fisik dengan mudah (9). Brisk walking dianggap aman bagi kebanyakan orang dan direkomendasikan bagi

\footnotetext{
1 Postgraduate Program, Faculty of Nursing, Hasanuddin University 5,6 Public Health Faculty, Hasanuddin 
orang-orang yang khawatir melakukan aktivitas fisik berat yang mudah menyebabkan cedera (10).

Beberapa studi menunjukkan brisk walking memiliki manfaat yang sangat beragam bagi kesehatan. Brisk walking efektif mengontrol gula darah pada pasien hipertensi usia paruh baya laki-laki (11). Memperbaiki dan mengontrol beberapa faktor risiko kardiovaskular di antara individu yang kelebihan berat badan atau obesitas (12), meningkatkan kekuatan otot, kinerja fisik dan komposisi tubuh (13). Efektif menurunkan ansietas pada pasien dengan hipertensi (14), serta efektif sebagai upaya pencegahan jatuh di komunitas dan beragam manfaat lainnya (15).

Berdasarkan pengamatan peneliti tidak ada kesimpulan atau hasil review yang jelas yang merangkum beragam manfaat dari brisk walking berdasarkan evidence based. Penggunaan brisk walking yang sudah cukup popular dan telah memiliki beragam bukti efektivitas dalam penggunaanya maka dibutuhkan sebuah studi untuk merangkum manfaat tersebut. Dengan demikian, kami melakukan tinjauan sistematis literatur untuk menawarkan kepada pembaca snapshot dari manfaat dan efektivitas brisk walking pada beragam kondisi pasien.

\section{Metode Penelitian}

Metode yang digunakan dalam penulisan ini adalah literature review yang merupakan laporan yang berisi tentang suatu topik yang telah dipublikasikan sebelumnya oleh para sarjana dan para peneliti dengan tujuan memperluas pengetahuan mengenai suatu topik. Selain itu, literatur review juga meningkatkan kemampuan dalam hal pencarian informasi yaitu kemampuan untuk memindai literatur secara efisien. Serta melakukan penilaian kritis yaitu kemampuan untuk menerapkan prinsip-prinsip analisis untuk mengidentifikasi studi yang tidak bias dan valid (16). Pencarian dilakukan diempat data base yaitu PubMed, ScienceDirect, Scopus dan ProQuest. Pertanyaan penelitian terstruktur menggunakan metode elektronik PICO (patient, intervention, comparison and outcome) (17) (18). PICO dalam artikel ini adalah P: tidak ditentukan, I: Brisk Walking, C: tidak ditententukan pembanding atau kelompok kontrol, dan 0: keefektifan penggunaannya.

Sebanyak 729 artikel yang diidentifikasi dari ke empat pencarian database yang telah difilter 5 tahun terakhir, penelitian dilakukan pada manusia dan berbahasa inggris. Namun, setelah dilakukan screening dari 729 artikel didapatkan sebanyak 40 artikel yang sesuai dengan judul penelitian ini. Dari 40 artikel yang sesuai dengan judul penelitian 31 artikel dieksklusi dikarenakan tidak sesuai kriteria inklusi yaitu doubel publikasi $(n=11)$, desain non RCT $(n=8)$, bukan hasil penelitian (7), abstrak $(n=5)$. Sehingga terdapat 8 artikel yang memenuhi kriteria inklusi yang keseluruhannya menggunakan desain penelitian RCT. Artikel yang diinklusi untuk tinjauan literatur ini adalah artikel yang (1) fokus pada penggunaan intervensi brisk walking (2) ditulis dalam bahasa Inggris (3) dipublikasikan 5 tahun terakhir dan (4) artikel menggunakan desain penelitian RCT.

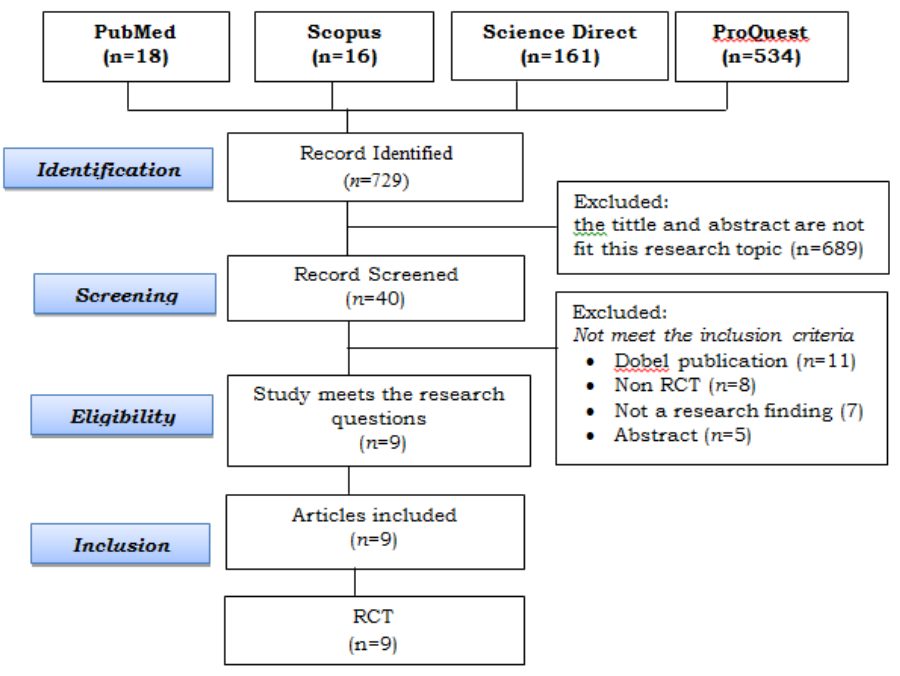

Bagan 1. Alur Pencarian dan Seleksi Artikel 


\section{Hasil Penelitian}

\section{Metode}

Beberapa penelitian telah dilakukan untuk mengevaluasi keefektifan brisk walking dalam berbagai kondisi kesehatan pasien. Kami merangkum 9 artikel yang memenuhi kriteria inklusi tentang intervensi brisk walking, jurnal 5 tahun terakhir dan berbahasa inggris. Dari 9 artikel yang diinklusikan, seluruhnya menggunakan desain RCT dengan masing-masing berasal dari Negara Taiwan $(n=2)$, Hongkong, Czech Republic, Prancis $(n=2)$, China dan Malaysia $(n=2)$.

\section{Sampel}

Dari 9 artikel yang diinklusikan, penggunaan sampel cukup beragam. Penelitian yang dilakukan oleh Huang et al., (2019) menggunakan 159 responden didiagnosis dengan kanker payudara stadium IIII. Penelitian Chan et al., (2018) memiliki responden sebanyak 246 orang penderita hipertensi. Penelitian Gába et al., (2016) Sebanyak 131 wanita yang yang sedentary (kurang aktivitas fisik). Penelitian lain Wu et al., (2015) sebanyak 86 responden yang bekerja di industri tingkat tinggi.

Selanjutnya, penelitian Blain et al., (2017) dan Bernard et al., (2018) dilakukan pada 121 responden wanita usia lanjut yang sedentary. Penelitian dari Sun et al., (2018) menggunakan 48 responden dengan kriteria lansia. Adapun Chen, Ismail, \& Safi (2016) Sebanyak 54 peserta dengan obesitas. Penelitian Abdullah et al., (2016) menggunakan 45 peserta dengan hipertensi esensial (tekanan darah istirahat antara 130/85 mmHg dan 159/99 $\mathrm{mmHg}$ ) dan BMI kurang dari $30 \mathrm{Kg} / \mathrm{m} 2$.

Intervensi Brisk Walking

\begin{tabular}{|c|c|c|c|}
\hline Referensi & Intervensi & Durasi & Lama Intervensi \\
\hline $\begin{array}{l}\text { Huang et al., (2019) } \\
\text { Taiwan }\end{array}$ & $\begin{array}{l}\text { Intensitas latihan brisk } \\
\text { walking tingkat sedang dan } \\
\text { meningkat (bertahap) } 30 \%- \\
70 \% \text { persentase detak } \\
\text { jantung dicadangkan. }\end{array}$ & $\begin{array}{l}\text { 15-25 /menit } \\
\text { hingga 35- } \\
40 / \text { menit. } \\
\text { 3-5 } \\
\text { kali/Minggu }\end{array}$ & 12 Minggu \\
\hline $\begin{array}{l}\text { Chan et al., (2018) } \\
\text { Hongkong }\end{array}$ & $\begin{array}{l}\text { Berjalan antara } 5-6 \mathrm{~km} \mathrm{/} \\
\text { jam. }\end{array}$ & $\begin{array}{l}30 \text { menit, } \\
5 \text { kali/ Minggu }\end{array}$ & 12 Minggu \\
\hline $\begin{array}{l}\text { Gába et al., (2016) } \\
\text { Czech Republic }\end{array}$ & $\begin{array}{l}\text { Brisk walking ke atau dari } \\
\text { tempat kerja }\end{array}$ & $\begin{array}{l}\text { 30-35 menit, } 5 \\
\text { kali/ minggu }\end{array}$ & $10 \mathrm{Minggu}$ \\
\hline $\begin{array}{l}\text { Wu et al., (2015) } \\
\text { Taiwan }\end{array}$ & $\begin{array}{l}\text { Jalan cepat menempuh jarak } \\
\text { yang sama. }\end{array}$ & $\begin{array}{l}45-60 \text { menit, } 2 \\
\text { kali/ minggu }\end{array}$ & $8 \mathrm{Minggu}$ \\
\hline $\begin{array}{l}\text { Blain et al., (2017) } \\
\text { Prancis }\end{array}$ & $\begin{array}{l}\text { Brisk walking dengan } 40 \% \\
\text { denyut jantung maks. } \\
\text { bertahap meningkat } 60-80 \%\end{array}$ & $\begin{array}{l}50 \text { menit, } 3 \\
\text { kali/ minggu }\end{array}$ & 6 Bulan \\
\hline $\begin{array}{l}\text { Bernard et al., (2018) } \\
\text { Prancis }\end{array}$ & $\begin{array}{l}\text { Brisk walking dengan denyut } \\
\text { jantung maks. bertahap } \\
\text { meningkat } 60-80 \%\end{array}$ & $\begin{array}{l}60 \text { menit, } 3 \\
\text { kali/ minggu }\end{array}$ & 6 Bulan \\
\hline $\begin{array}{l}\text { Sun et al., (2018) } \\
\text { China }\end{array}$ & $\begin{array}{lll}\text { Brisk Walking: } & \text { Durasi } \\
\text { berjalan meningkat } & \text { setiap } \\
\text { sesi } & & \end{array}$ & $\begin{array}{lr}10 & \text { menit } \\
\text { hingga } & 40 \\
\text { menit, } & 5 \\
\text { kali/minggu } & \end{array}$ & 16 Minggu \\
\hline $\begin{array}{l}\text { Chen, Ismail, \& Safi } \\
\text { (2016) } \\
\text { Malaysia }\end{array}$ & $\begin{array}{l}\text { Brisk walking dilakukan pada } \\
60-70 \% \text { dari perkiraan } \\
\text { denyut jantung maksimum }\end{array}$ & 3 kali/ minggu & 8 Minggu \\
\hline $\begin{array}{l}\text { Abdullah et al., (2016) } \\
\text { Malaysia }\end{array}$ & $\begin{array}{l}\text { Parameter terdiri dari } \\
\text { jalan cepat di treadmill } \\
\text { dengan metode interval }\end{array}$ & $\begin{array}{l}45 \text { menit, } 4 \\
\mathrm{kali} / \mathrm{minggu}\end{array}$ & 4 Minggu \\
\hline
\end{tabular}




\author{
aerobic. Kelompok dibagi \\ berdasarkan intensitas \\ rendah, sedang dan tinggi
}

Tabel 1. Pelaksanaan Intervensi Brisk Walking dari Beragam Referensi

Brisk walking diterapkan dengan tingkat sedang hingga tinggi, dan ditingkatkan secara bertahap. Durasi umum setiap sesi latihan minimal 10 menit dan dapat ditingkatkan hingga maksimal 60 menit. Efek penggunaan brisk walking setidaknya menunjukkan efektivitas pada 1 bulan hingga 6 bulan setelah latihan.

\title{
Efektivitas Brisk Walking
}

Berdasarkan 9 artikel yang telah dianalisis, beberapa manfaat yang telah terbukti efektif berdasarkan evidence based adalah untuk mengurangi tingkat kelelahan terutama pada pasien dengan kanker payudara yang menjalani kemoterapi (19) dan para pekerja industri tingkat tinggi (22). Mengurangi risiko kardiovaskular pada pasien, efektif mengurangi kadar gula darah (20) (12), efektif menurunkan tekanan darah terutama pada latihan intensitas tingkat sedang (26). Efektivitas brisk walking lainnya diantaranya, mencegah penurunan stabilitas postural dan mengurangi risiko jatuh dan meningkatkan kemampuan keseimbangan lansia dan daya tahan berjalan (toleransi olahraga) hingga 45\% (21) (23) (25).

\section{Diskusi}

\section{Metode}

Desain penelitian RCT adalah yang paling sesuai digunakan untuk menguji efektivitas suatu intervensi, karena RCT merupakan desain eksperimental klasik. terencana yang dirancang dengan memberikan intervensi pada manusia dengan membandingkan intervensi dengan kelompok kontrol ditentukan murni secara kebetulan (randomisasi) (27). RCT menggunakan metode hipotesis dengan pengujian yang ketat secara ilmiah dan dianggap sebagai gold standard untuk mengevaluasi keefektifan intervensi (28) (29).

\section{Sampel}

Hasil telaah literatur didapatkan jumlah sampel berkisar antara 48-246 atau rata rata jumlah sampel yang sering digunakan dalam artikel adalah $>100$ sampel yang disebar dalam 2 kelompok. Hal ini sesuai dengan teori yang mengatakan bahwa kekuatan statistik dari RCT salah satunya ditentukan oleh ukuran sampel, ukuran sampel harus cukup besar atau cukup banyak peserta di setiap kelompok (28).

Penentuan ukuran sampel yang memadai merupakan aspek penting saat melakukan RCT. Penting untuk memilih ukuran kriteria inklusi dan eksklusi yang dapat diandalkan dan valid sehingga sampel penelitian mencerminkan populasi yang diminati (30).

\section{Intervensi Brisk Walking}

Brisk walking merupakan salah satu bentuk latihan aerobic (moderate activity) yang direkomendasikan. Penggunaan intervensi ini dilakukan secara bertahap mulai dari 15 menit setiap sesi dan perlahan ditingkatkan (31). Bahkan brisk walking dengan durasi setidaknya 10 menit/hari terbukti efektif bermanfaat bagi kesehatan (32) (9). Hal ini sesuai dengan referensi dari artikel yang telah dianalisis sebelumnya.

\section{Efektivitas Brisk Walking}

Brisk walking menjadi aktivitas pilihan bagi jutaan orang. Aktivitas fisik yang teratur ini akan membantu mencegah kematian dini dan penyakit kronis seperti penyakit jantung koroner, stroke, Diabetes tipe 2, depresi, dan beberapa jenis kanker. Penelitian menunjukkan bahwa setiap orang yang melakukan aktivitas fisik yang teratur dapat meningkatkan harapan hidup (32). 
Brisk walking umumnya aman bagi kebanyakan orang (33). Bukti telah menunjukkan manfaat kesehatan setidaknya 10 menit brisk walking per hari atau 70-90 menit per minggu. Manfaat tersebut berupa peningkatan kebugaran fisik, kemudahan kinerja kegiatan fisik sehari-hari, suasana hati membaik, kualitas hidup meningkat serta mengurangi $15 \%$ risiko kematian dini (9). Beragam manfaat tersebut juga telah dibuktikan dalam artikel yang telah dianalisis sebelumnya.

\section{Kesimpulan}

Literature review ini memberikan gambaran tentang beragam manfaat dari brisk walking diantaranya, mengurangi tingkat kelelahan, menurunkan risiko kardiovaskular (termasuk hipertensi), mencegah penurunan stabilitas postural dan mengurangi risiko jatuh dan meningkatkan kemampuan keseimbangan lansia. Latihan ini dapat juga dianjurkan bagi siapa saja yang ingin hidup sehat dan direkomendasikan untuk dapat dilakukan di rumah dengan pelaksanaan yang sesuai rekomendasi.

\section{Daftar Pustaka}

1. WHO. Fact sheets on sustainable development goals: health targets [Internet]. Denmark: World Health Organization Regional Office for Europe; 2017. Available from: https://www.euro.who.int/_data/assets/pdf_file/0007/350278/Fact-sheet-SDG-NCDFINAL-25-10-17.pdf?ua=1

2. WHO. Health statistics and information systems [Internet]. 2016. Available from: https://www.who.int/healthinfo/global_burden_disease/en/

3. WHO. United Nations high-level meeting on noncommunicable disease prevention and control [Internet]. 2011. Available from: https://www.who.int/nmh/events/un_ncd_summit2011/en/

4. Gowshall M, Taylor-Robinson SD. The increasing prevalence of non-communicable diseases in low-middle income countries: the view from Malawi. Int J Gen Med [Internet]. 2018;11. Available from: https://www.ncbi.nlm.nih.gov/pmc/articles/PMC6029598/

5. WHO. Global Recommendations on Physical Activity for Health [Internet]. 2010. Available from:

https://apps.who.int/iris/bitstream/handle/10665/44399/9789241599979_eng.pdf?sequ ence $=1$

6. González K, Fuentes J, Márquez JL. Physical Inactivity, Sedentary Behavior and Chronic Diseases. Korean J Fam Med [Internet]. 2017;38(3). Available from: https://www.ncbi.nlm.nih.gov/pmc/articles/PMC5451443/

7. Yang YJ. An Overview of Current Physical Activity Recommendations in Primary Care. Korean J Fam Med [Internet]. 2019;40(3). Available from: https://www.ncbi.nlm.nih.gov/pmc/articles/PMC6536904/

8. The U.S. Department of Health and Human Services. Physical Activity Guidelines for Americans 2nd edition [Internet]. 2018. Available from: https://health.gov/sites/default/files/2019-

09/Physical_Activity_Guidelines_2nd_edition.pdf

9. Public Health England. 10 minutes brisk walking each day in mid-life for health benefits and towards achieving physical activity recommendations Evidence summary [Internet]. 2017. Available

from: https://assets.publishing.service.gov.uk/government/uploads/system/uploads/attachmen t_data/file/639030/Health_benefits_of_10_mins_brisk_walking_evidence_summary.pdf

10. CDC. Benefits of Physical Activity [Internet]. 2020. Available from: https://www.cdc.gov/physicalactivity/basics/pa-health/index.htm 
11. Manivannan, Prabhusaran, Sundhararajan, Elangovan. Effectiveness of Yoga and Brisk Walking On Blood Sugar among Hypertensive Men. Int J Innov Sci Eng Technol [Internet]. 2016;3(1). Available from: http://ijiset.com/vol3/v3s1/IJISET_V3_I1_37.pdf

12. Chen CK, Ismail NS, Syafi AA Al. Effects of brisk walking and resistance training on cardiorespiratory fitness, body composition, and lipid profiles among overweight and obese individual. ournal Phys Educ Sport [Internet]. 2016;16(3). Available from: https://www.researchgate.net/publication/308898452_Effects_of_brisk_walking_and_resis tance_training_on_cardiorespiratory_fitness_body_composition_and_lipid_profiles_among_o verweight_and_obese_individuals

13. Rossi AP, Rubele S, Pelizzari L, Fantin F, Morgante S, Marchi O, et al. Effects of Brisk Walking on Physical Performance and Muscle Function in Community Dwelling Elderly Women. J Gerontol Geriatr Res [Internet]. 2017;6. Available from: https://www.longdom.org/openaccess/effects-of-brisk-walking-on-physical-performance-and-muscle-function-incommunity-dwelling-elderly-women-2167-7182-1000399.pdf

14. Manivannan, Prabhusaran, Elangovan. Effect of yogic practices and brisk walking on anxiety among hypertensive men. Int J Med Heal Res. 2015;1(5).

15. Okubo Y, Osuka Y, Jung S, Rafael F, Tsujimoto T, Aiba T, et al. Walking can be more effective than balance training in fall prevention among community-dwelling older adults. Geriatr Gerontol Int. 2016;16(1).

16. Taylor D. The Literature Review: A Few Tips On Conducting It. Writing Advice. 2020.

17. Frandsen TF; Eriksen MB. The impact of PICO as a search strategy tool on literature search quality: A systematic review. J Med Libr Assoc. 2018;106(In press):420-31.

18. Santos CM da C, Pimenta CA de M, Nobre MRC. The PICO strategy for the research question construction and evidence search. Rev Lat Am Enfermagem. 2007;15(3):508-11.

19. Huang H-P, Wen F-H, Yang T-Y, Lin Y-C, Tsai J-C, Shun S-C, et al. The effect of a 12-week home-based walking program on reducing fatigue in women with breast cancer undergoing chemotherapy: A randomized controlled study. Int J Nurs Stud. 2019;99.

20. Chan AWK, Chair SY, Lee DTF, Leung DYP, Sit JWH, Cheng HY, et al. Tai Chi exercise is more effective than brisk walking in reducing cardiovascular disease risk factors among adults with hypertension: A randomised controlled trial. Int J Nurs Stud. 2018;88.

21. Gába A, Cuberek R, Svoboda Z, Chmelík F, Pelclová J, Lehnert M, et al. The effect of brisk walking on postural stability, bone mineral density, body weight and composition in women over 50 years with a sedentary occupation: a randomized controlled trial. BMC Womwns Heal. 2016;16.

22. Wu L-L, Wang K-M, Liao P-I, Kao Y-H, Huang Y-C. Effects of an 8-Week Outdoor Brisk Walking Program on Fatigue in Hi-Tech Industry Employees: A Randomized Control Trial. Workplace Health Saf. 2015;63(10).

23. Blain H, Jaussent A, Picot M-C, Maimoun L, Coste O, Masud T, et al. Effect of a 6-Month Brisk Walking Program on Walking Endurance in Sedentary and Physically Deconditioned Women Aged 60 or Older: A Randomized Trial. J Nutr Heal Aging. 2017;21(10).

24. Bernard PL, Blain H, Tallon G, Ninot G, Jaussent A, Picot MC, et al. Influence of a brisk walking program on postural responses in sedentary older women: a randomised trial. Aging Clin Exp Res. 2018;30(5).

25. Sun W, Ma X, Wang L, Zhang C, Song Q, Gu H, et al. Effects of Tai Chi Chuan and Brisk Walking Exercise on Balance Ability in Elderly Women: A Randomized Controlled Trial. Hum Kinet J. 2018;23(1).

26. Abdullah MR, Eswaramoorthi V, Musa RM, Maliki ABHM, Kosni NA, Haque M. The 
Effectiveness of Aerobic Exercises at difference Intensities of Managing Blood Pressure in Essential Hypertensive Information Technology Officers. J Young Pharm [Internet]. 2016;8(4). Available from: http://www.jyoungpharm.org/article/912

27. Renjith V. Review papers Blinding in Randomized Controlled Trials: What researchers need to know? Manipal J Nurs Heal Sci. 2017;3(1).

28. Akobeng AK. Understanding Randomised Controlled Trials. Arch Dis Child. 2005;90:840-4.

29. Hariton E, Locascio JJ. Randomised controlled trials-the gold standard for effectiveness research. BJOG [Internet]. 2018;125(13). Available from: https://www.ncbi.nlm.nih.gov/pmc/articles/PMC6235704/pdf/nihms966617.pdf

30. Saxena P, Prakash A, Acharya AS, Nigam A. How to design and conduct a Randomised Controlled Trial? Indian J Med Spec [Internet]. 2012;3(2). Available from: https://www.researchgate.net/publication/233721604_How_to_design_and_conduct_a_Ra ndomised_Controlled_Trial

31. WHO. Global Recommendations on Physical Activity fo Health. 2010.

32. American Heart Association. Warm Weather Fitness Guide : Your Path to Heart Health. 2012.

33. Center for Disease Control and Prevention. Benefit of Physical Activity. Physical Activity. 2020. 